\title{
Design and manufacture of electromagnetic absorber composed of boric acid-incorporated wastepaper composites
}

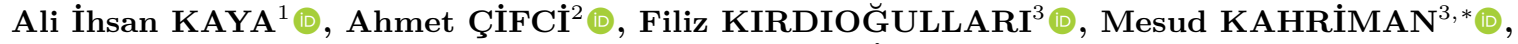 \\ Osman ÇEREZCI ${ }^{4}$ (D) \\ ${ }^{1}$ Department of Design, Vocational School of Technical Sciences, Burdur Mehmet Akif Ersoy University, \\ Burdur, Turkey \\ ${ }^{2}$ Department of Electrical-Electronics Engineering, Faculty of Engineering and Architecture, \\ Burdur Mehmet Akif Ersoy University, Burdur, Turkey \\ ${ }^{3}$ Department of Electrical-Electronics Engineering, Faculty of Engineering, Suleyman Demirel University, \\ Isparta, Turkey \\ ${ }^{4}$ Department of Electrical-Electronics Engineering, Faculty of Engineering and Natural Sciences, \\ Uskudar University, İstanbul, Turkey
}

\begin{abstract}
Received: 04.06 .2021
Accepted/Published Online: 23.10 .2021

Final Version: 21.03.2022

Abstract: With the effect of technological advances, the use of electrical and electronic devices has increased dramatically in recent years. Wireless technologies and related applications are mostly preferred for the communication of these devices with each other. Thus, people are easily exposed to electromagnetic waves in daily life. The extensive global use of these devices raises the question of their possible biological effects on human health. Also, electromagnetic waves influence the functioning of a nearby device. In this study, an electromagnetic absorber based on boric acid (5, 10, 20, and $30 \mathrm{wt} \%)$ added wastepaper was developed. Copper $(\mathrm{Cu})$ and aluminum (Al) were also used as mineral additives for comparison. Three different kinds of wastepaper namely, office paper, newsprint, and cardboard paper were selected for the experimental study. The effect of varying boric acid contents on the electromagnetic absorption of the boards manufactured was evaluated and compared to $\mathrm{Cu}(30 \mathrm{wt} \%)$ and $\mathrm{Al}(30 \mathrm{wt} \%)$ added boards. The results show that newsprint has better absorption effectiveness than office and cardboard paper and absorption up to $40 \mathrm{~dB}$ was achieved. The absorption effectiveness of $\mathrm{Al}, \mathrm{Cu}$, and boric acid added boards was achieved at approximately 40, 30, and 20 dB, respectively. As a result, the electromagnetic absorption effectiveness of boric acid added the board is acceptable levels. Also, apart from the use of boric acid as a powder, it has been determined that the application of the surface as a layer is effective in absorption.
\end{abstract}

Key words: boric acid, composite material, electromagnetic absorber, wastepaper

\section{Introduction}

Electromagnetic waves in radio frequency $(\mathrm{RF})$ and microwave frequencies cause to prevent the correct operation of devices by affecting sensitive electronic devices as well as biological effects on human health[1-4]. An electromagnetic wave absorption process is required to prevent these adverse effects. There are many materials developed to minimize the possible effects of electromagnetic waves in RF and microwave frequencies [5-10]. The requirements in the selection of these materials are electromagnetic effectiveness, environmentally friendly and being economical. Electromagnetic absorbing materials like composites through the minerals added to their structures can absorb electromagnetic waves effectively.

*Correspondence: mesudkahriman@sdu.edu.tr 
KAYA et al./Turk J Elec Eng \& Comp Sci

As a word, composite means consisting of two or more parts [11]. Composite materials are materials composed of two or more components that are macro separated from each other and have an interface between these components. The components retain their properties in the composite. They originated in situations where traditional materials were inadequate. Composite materials are relatively new and advanced technology materials when evaluated in terms of materials science and their use is spreading rapidly. The most important feature of the composite material is its homogeneity at the micro-level and it differs from the alloy with this feature. Composite materials are materials that are brought together to improve their existing properties. Composite materials consist of a matrix main phase and reinforcing elements dispersed therein.

Springer et al. [12] developed a new material called economic block in order to solve the environmental problem caused by wastepaper. The wastepaper pulp pressed into aluminum molds with the help of heat was dried, and blocks of $5 \mathrm{~cm} \times 10 \mathrm{~cm} \times 20 \mathrm{~cm}$ were obtained and they compared this material with other blocks. They have made suggestions on the technical and economic evaluation of the properties of the material. Davis and Song [13], in their study, used chemical components in the wastewater formed during ink removal in the recycling of wastepaper. They explained that these waters contain $11 \%$ silicon, $10 \%$ aluminum, $4 \%$ calcium, and $2 \%$ titanium and the addition of $6 \%$ phenol formaldehyde as a binder used in fiberboard production system affects the properties of the boards within acceptable limits. Fugetsu et al.[14] investigated the electrical conductivity of a composite material consisting of $8.32 \%$ carbon nanotubes contribution by weight to cellulose fibers and the electromagnetic absorption property in the range of 15-40 GHz. As a result, they found the electrical conductivity of $5.3 \times 10^{-1} \Omega \mathrm{cm}$ and obtained effective electromagnetic shielding in the $30-40 \mathrm{GHz}$ test range. In [15], Sangrutsamee et al. made composite blocks from wastepaper, cement, and sand. They examined the water absorption capability and thermal conductivity of this material. In the study, they used newspaper paper, office paper, cardboard paper and their mixtures in different proportions.

As a result of the advances in technology, the use of electromagnetic wave generating devices is becoming widespread day by day, and thus people are exposed to electromagnetic waves in daily life $[16,17]$. The adverse effects caused by electromagnetic waves are still open to question since there is no clear and direct evidence of its possible effects on human health. A multi-layer electromagnetic wave absorber consisting of sintered ferrite or ferrite composite membrane has been introduced by Naito et al. in [18]. The electric field uniformity was improved in the frequency range of 800-1000 MHz. See also [19], where authors designed two kinds of lowfrequency broadband metamaterial microwave absorbers. Absorption rates of both absorbers exceed $90 \%$ in the range of approximately 300-1000 MHz. Håkanssona et al. [20] measured the heat increase and electromagnetic shielding occurring at short wavelengths in conductive coated fabrics. As a result, they found that there was a large temperature increase in samples with low conductivity. Raju [21] prepared zinc ferrite particles and studied the electromagnetic properties of particles in the frequency range from $1 \mathrm{MHz}$ to $1.8 \mathrm{GHz}$. He found that these ferrites showed a potential application as multiband electromagnetic wave absorbers. Kaya et al. [22] produced a composite material from the recycling of Tetra Pak beverage cartons to absorb the electromagnetic interference and investigated the effect of aluminum additive on absorption efficiency of electromagnetic interference at different frequencies. Wang et al. [23], in their study, created paper-based metasurfaces by recycling wastepaper to eliminate electromagnetic pollution. Their experimental measurements and simulations have shown that the wastepaper-based metasurfaces produced in this way exhibit remarkable electromagnetic shielding properties at small thicknesses. Çifci and Kaya [24] produced a conductive mineral powders based wastepaper boards as a shielding material and investigated its electromagnetic interference shielding effectiveness. They showed that the shielding effectiveness of the board is directly related to the conductivity of that board. 
KAYA et al./Turk J Elec Eng \& Comp Sci

In this paper, the boric acid-incorporated wastepaper (office paper, newsprint, and cardboard paper) was selected as the research object of this paper and consequently, the effects of 5, 10, 20, and 30 wt\% boric acid additions on electromagnetic absorption were investigated. $\mathrm{Cu}$ and $\mathrm{Al}$ were also used as absorbents. An absorption effectiveness comparison was made between boric acid and $\mathrm{Cu}$, Al. This work suggests that the boric acid added wastepaper composite could be a candidate material for absorbers applications.

The following sections are organized as follows: The next section presents the manufacturing process of samples. The electromagnetic absorption measurement setup is outlined in section 3 . Section 4 gives the recorded results. The last section is the conclusion.

\section{Sample preparation}

In this present study, wastepaper fibers (office paper, newsprint, and cardboard paper) with low economic value and obtained from recycling were used as reinforcement elements. These three paper fibers formed the main structure in composite material manufacture. A separate composite material was manufactured for each paper fiber, and the difference between them was demonstrated experimentally. Paper fibers were obtained from recycling collection centers and were separated according to their types.

Urea-formaldehyde (UF) resin with chemical addition of free formaldehyde holder, which is a polymerbased thermoset resin, was used as a binder and matrix material. UF resins are thermoset polymers formed as a result of the polycondensation of urea and formaldehyde. They are preferred due to their high reactivity and low-cost advantages. However, under normal conditions, UF resin releases an undesirable amount of formaldehyde. For this reason, in the study, the formaldehyde-retaining resin with a low formaldehyde release level was obtained from Polisan Kimya. The emission value of the manufactured boards is determined according to the European E0 class and the Japanese Standard JIS A5905 F*** ( $\leq 0.5 \mathrm{mg} / \mathrm{L})$. The properties of the UF used are presented in Table 1.

Boric acid was used as a mineral additive in the study. The absorption effectiveness of copper $(\mathrm{Cu})$ and aluminum (Al) was also measured in order to compare the absorption effectiveness of boric acid. Boric acid used in the study was provided in pure form from BSA Kimya. Boric acid was added to the boards at the rate of $0 \%, 5 \%, 10 \%, 20 \%$, and $30 \%$ by weight according to the paper fiber ratio during the board manufacturing process. The physical properties of boric acid are shown in Table 2.

Table 1. Properties of UF

\begin{tabular}{|l|l|l|}
\hline Properties & Unit & UF. \\
\hline Solid content & $\%$ & $63 \pm 1$ \\
\hline Density & $\mathrm{g} / \mathrm{cm}^{3}$ & $1.27-1.29$ \\
\hline $\mathrm{pH}$ at $25^{\circ} \mathrm{C}$ & - & $7.5-8.5$ \\
\hline Viscosity at $25^{\circ} \mathrm{C}$ & $\mathrm{cps}$ & $350-500$ \\
\hline Gel point at $100^{\circ} \mathrm{C}$ & $\mathrm{s}$ & $25-30$ \\
\hline Storage time & day & 60 \\
\hline Flowing point at $25^{\circ} \mathrm{C}$ & $\mathrm{s}$ & $20-30$ \\
\hline Free $\mathrm{CH}_{2} \mathrm{O}(\mathrm{max})$ & $\%$ & 0.80 \\
\hline Formaldehyde/urea mole ratio & - & $0.88-1.03$ \\
\hline
\end{tabular}

Table 2. Properties of boric acid.

\begin{tabular}{|l|l|l|}
\hline Properties & Unit & Boric acid \\
\hline Specific weight & $\mathrm{g} / \mathrm{cm}^{3}$ & 1.51 \\
\hline Bulk density & $\mathrm{g} / \mathrm{cm}^{3}$ & 0.892 \\
\hline Molecular weight & $\mathrm{g} / \mathrm{mol}$ & 61.83 \\
\hline Melting point & ${ }^{\circ} \mathrm{C}$ & 450 \\
\hline Boiling point & ${ }^{\circ} \mathrm{C}$ & 1860 \\
\hline Thermal conductivity & $\mathrm{W} / \mathrm{mK}$ & 0.407 \\
\hline Heat capacity & $\mathrm{J} / \mathrm{gK}$ & 24.7 \\
\hline Magnetic susceptibility & $\mathrm{cm}^{3} / \mathrm{mol}$ & $-34.1 \times 10^{-6}$ \\
\hline
\end{tabular}


Boric acid (also called boracic acid or orthoboric acid) is a weak acid of boron. Its chemical formula is written as $\mathrm{H}_{3} \mathrm{BO}_{3}$ or $\left(\mathrm{B}(\mathrm{OH})_{3}\right)$ and is found in water-soluble form as a white powder. Boric acid is obtained by the reaction of colemanite ore with sulfuric acid or borax and a mineral acid [25]. $\mathrm{Al}$ and $\mathrm{Cu}$ powder used in this present study were obtained from Nanokar Nanomaterial Powder in pure form. $\mathrm{Al}$ and $\mathrm{Cu}$ were added to the boards at the rate of $30 \mathrm{wt} \%$ according to the paper fiber ratio during the board manufacturing process. The physical properties of $\mathrm{Al}$ and $\mathrm{Cu}$ are given in Table 3.

Table 3. Properties of $\mathrm{Al}$ and $\mathrm{Cu}$

\begin{tabular}{|l|l|l|l|}
\hline Properties & Unit & Al & Cu \\
\hline Specific weight & $\mathrm{g} / \mathrm{cm}^{3}$ & 2.70 & 8.96 \\
\hline Density in the liquid state & $\mathrm{g} / \mathrm{cm}^{3}$ & 2.375 & 8.02 \\
\hline Melting point & ${ }^{\circ} \mathrm{C}$ & 660 & 1084 \\
\hline Boiling point & ${ }^{\circ} \mathrm{C}$ & 2519 & 2562 \\
\hline Thermal conductivity & $\mathrm{W} / \mathrm{mK}$ & 237 & 401 \\
\hline Heat capacity & $\mathrm{J} / \mathrm{gK}$ & 24.2 & 24.44 \\
\hline Magnetic susceptibility & $\mathrm{cm}^{3} / \mathrm{mol}$ & $+16.5 \times 10^{6}$ & $-5.46 \times 10^{6}$ \\
\hline Electrical resistivity at $20^{\circ} \mathrm{C}$ & $\mathrm{n} \Omega \mathrm{m}$ & 26.5 & 16.78 \\
\hline Average particle size & $\mathrm{nm}$ & 50 & 50 \\
\hline
\end{tabular}

The wastepapers used in the study were evaluated by classifying each paper type separately. Office paper, newsprint, and cardboard paper were cut into smaller sizes as a preliminary preparation for the fiberizing process and turned into clippings. Figure 1 shows the manufacturing processes of the composite material.

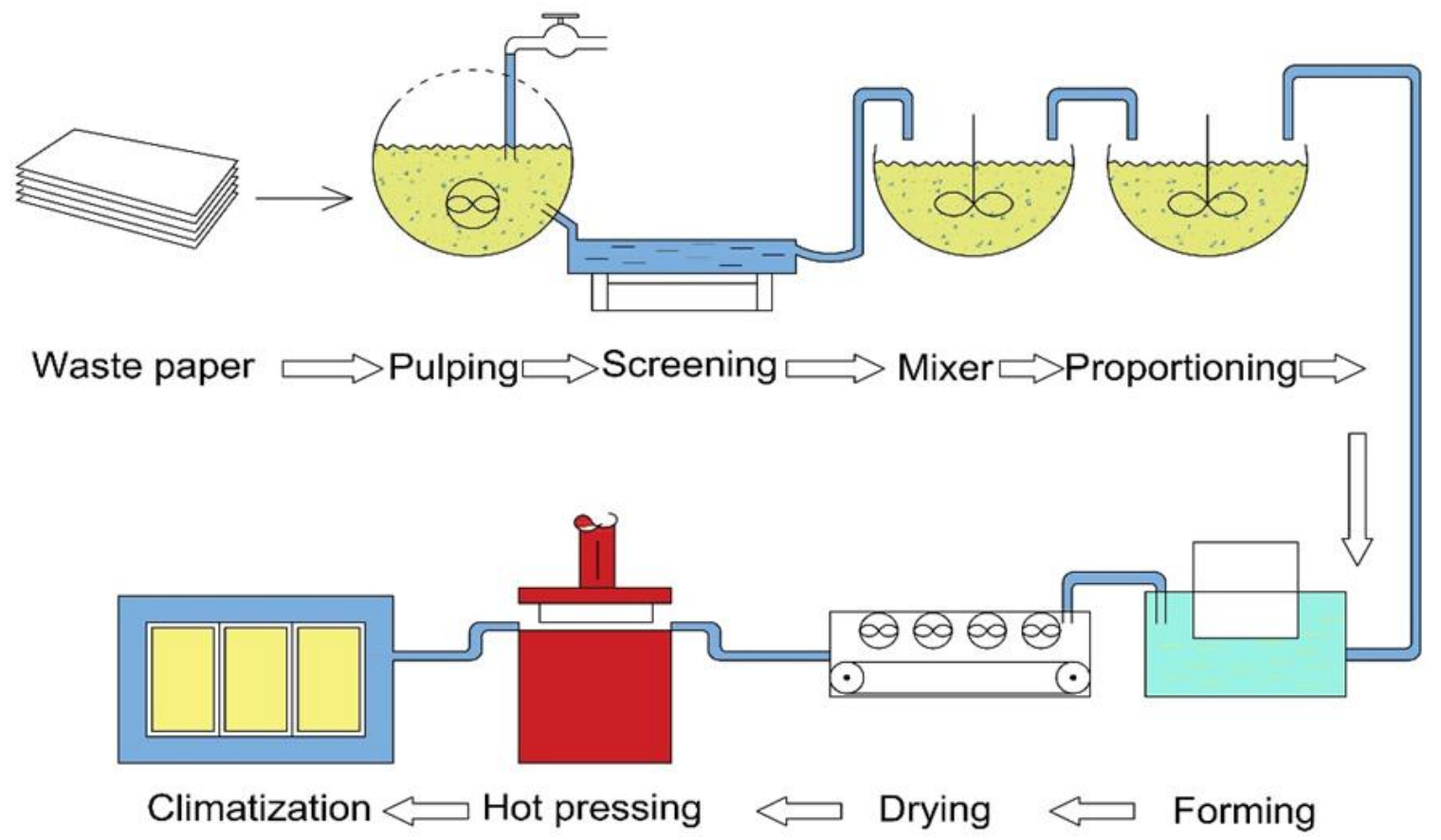

Figure 1. Flowchart of the manufacturing process of boards. 
The wastepapers in a clipped form with a solid concentration of $10 \%$ were kept in water at $20^{\circ} \mathrm{C}$ in separate containers. After this process called pulping, the fiberizing process was carried out in a mixer with a capacity of $1000 \mathrm{~cm}^{3}$, designed by TAPPI T $205 \mathrm{sp}-02$ standard [26] to ensure full opening of wastepaper fiber and homogeneous mixture. The purpose of the fiberizing process is to ensure that the wastepaper fibers gain the ability to bind.

The wastepaper pulp mixed in the mixer was poured into 100 mesh screens before the harmful biological activation started and subjected to the predrying process. Humidity content in any material is a predominant factor from an absorption point of view [27]. By starting the drying process, the relative humidity of solid waste was decreased from $100 \%$ to $60 \%-70 \%$. Samples whose relative humidity reached $60 \%-70 \%$ dryness in the predrying process were brought into contact with hot air $\left(220^{\circ} \mathrm{C}\right)$ moving at a speed of $28-30 \mathrm{~m} / \mathrm{s}$ in the drying oven. The fibers were brought to the dryness level required for board draft formation by reducing the relative humidity down to $7 \%-10 \%$.

At this stage, three different types of rough pulp draft at 7\%-10\% relative humidity were produced. The separation process was applied to rough pulp drafts in a stone mill for board manufacture. Separated fibers were classified in Bauer-McNett sieve and dried in a drying oven at $105 \pm 3{ }^{\circ} \mathrm{C}$ until constant humidity of $2 \%-3 \%$. The prepared board raw material and the inorganic mineral additive as matrix material was weighed in a certain proportion in a precision weighing scale and a different type of board draft was prepared. The samples prepared with $0 \%, 5 \%, 10 \%, 20 \%$ and $30 \%$ by weight of boric acid, $30 \mathrm{wt} \%$ of aluminum and $30 \mathrm{wt} \%$ of copper additives were poured into prepared molds by mixing homogeneously in a special type four-cylinder mixer. The board drafts thus obtained were firstly pre-pressed and then hot pressed. The properties of manufactured boards are specified in Table 4.

Table 4. Properties of manufactured boards

\begin{tabular}{|l|l|l|}
\hline Properties & Unit & Values \\
\hline Board sizes & $\mathrm{cm}$ & $20 \times 20$ \\
\hline Density & $\mathrm{g} / \mathrm{cm}^{3}$ & $0.65 \pm 0.05$ \\
\hline Matrix amount & $\%$ & 10 \\
\hline Hardening agent & $\%$ & 1 \\
\hline Hot press temperature & ${ }^{\circ} \mathrm{C}$ & $150-155$ \\
\hline Pressing time & $\mathrm{min}$ & 5 \\
\hline Press pressure & $\mathrm{N} / \mathrm{mm}^{2}$ & $3-3.5$ \\
\hline Thickness & $\mathrm{mm}$ & $11 \pm 0.05$ \\
\hline Humidity content & $\%$ & $3 \pm 0.1$ \\
\hline
\end{tabular}

Boards kept in the climatization process $\left(20^{\circ} \mathrm{C}\right.$ and humidity of $\left.65 \%\right)$ after the pressing process were made ready for the test phase. Especially in domestic applications, all board samples will be covered with a thin polyethylene film in order to eliminate the negative effects of the mineral substance on health as a result of dusting in the air. The board code-mixing ratio table of the boards for which electromagnetic absorption effectiveness will be determined is given in Table 5 .

Office paper samples, newsprint samples and cardboard paper samples which are manufactured in different types for experiments are shown in Figure 2, Figure 3, Figure 4, respectively.

Also, for comparison, a board containing $30 \%$ of aluminum and a board containing $30 \%$ of copper were produced by the surface coating method. 
KAYA et al./Turk J Elec Eng \& Comp Sci

Table 5. Board codes according to mixing ratios.

\begin{tabular}{|ll|ll|ll|l|l|}
\hline $\begin{array}{l}\text { Board Paper } \\
\text { code }\end{array}$ fiber & \multicolumn{2}{|l|}{$\begin{array}{l}\text { Board Paper } \\
\text { code fiber }\end{array}$} & \multicolumn{2}{|l|}{$\begin{array}{l}\text { Board Paper } \\
\text { code }\end{array}$ fiber } & Boric acid & additive in \% & $\begin{array}{l}\text { UF additive } \\
\text { in \% }\end{array}$ \\
\hline O0 & & N0 & C0 & & 0 & 10 \\
\hline O1 & Office & N1 & C1 & Cardboard & 5 & 10 \\
\hline O2 & (white) & N2 & Newsprint & C2 & (corrugated) & 10 & 10 \\
\hline O3 & paper & N3 & C3 & paper & 20 & 10 \\
\hline O4 & & N4 & C4 & & 30 & 10 \\
\hline
\end{tabular}

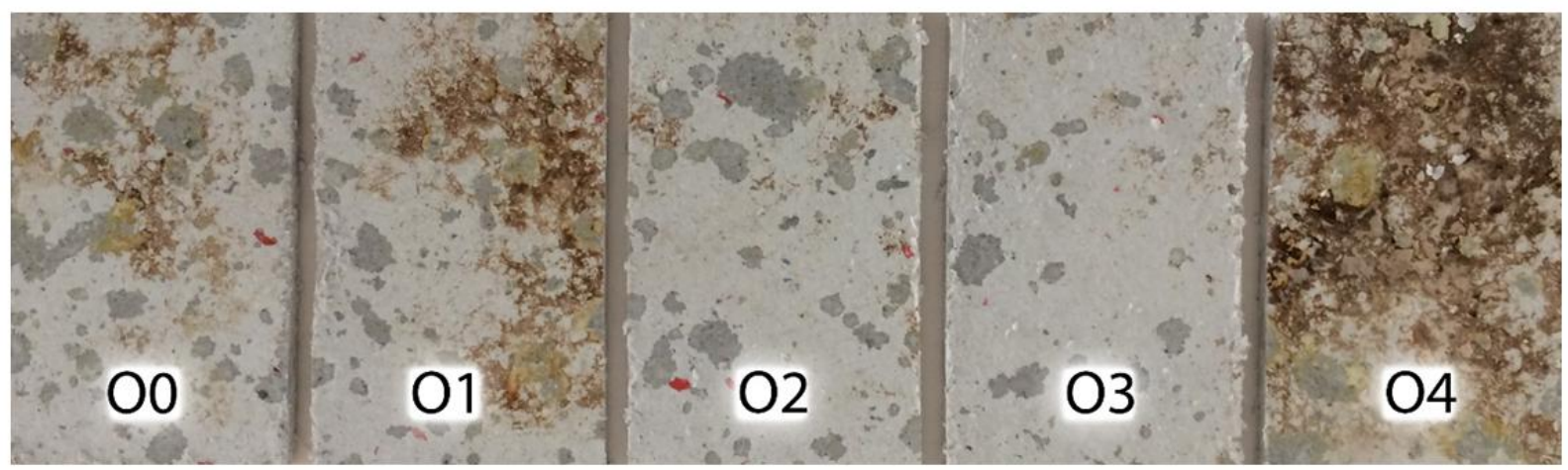

Figure 2. Office paper boards containing $0 \%, 5 \%, 10 \%, 20 \%$, and $30 \%$ of boric acid.

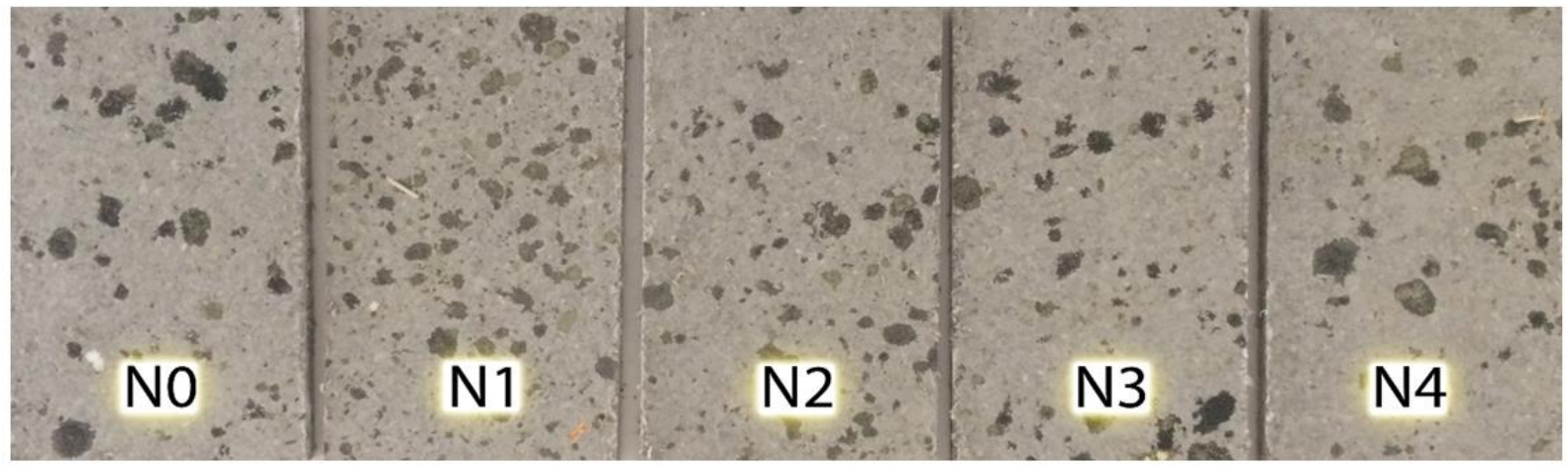

Figure 3. Newsprint boards containing 0\%, 5\%, 10\%, 20\%, and 30\% of boric acid.

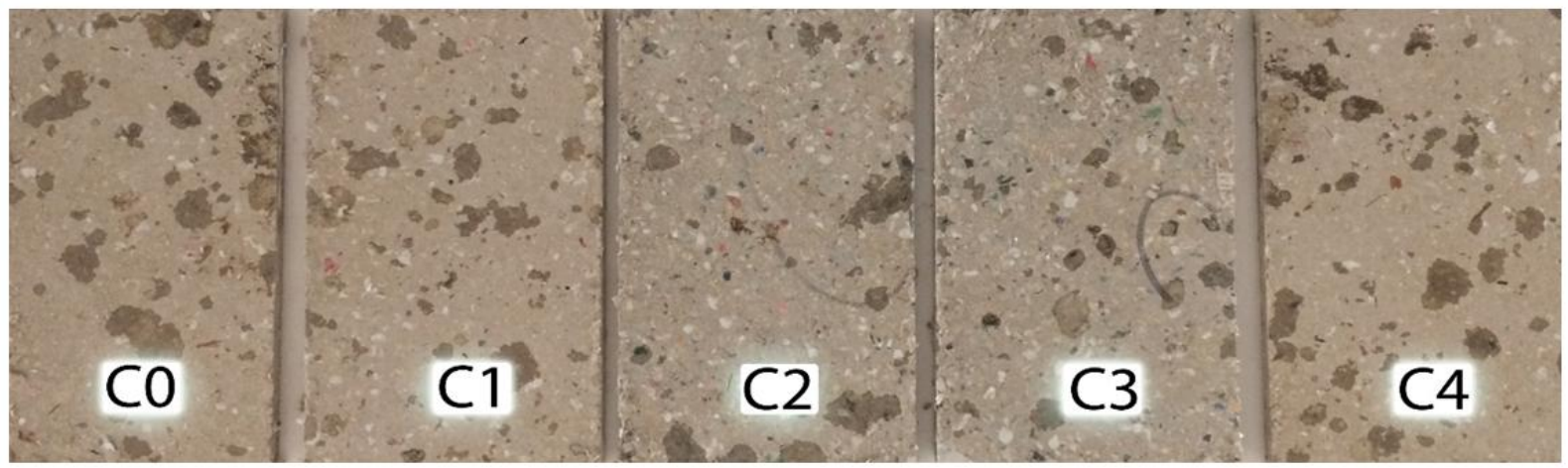

Figure 4. Cardboard paper boards containing 0\%, 5\%, 10\%, 20\% and $30 \%$ of boric acid. 


\section{Electromagnetic absorption measurements}

Electromagnetic absorption is a subject of research and application in different disciplines. The standards for measuring electromagnetic absorption are published by IEEE [28]. These standards were taken into consideration as a basis in the study. Geetha et al. [29] classified the methods used in electromagnetic absorption as coaxial transmission line method, shielded box method, shielded room method and open field or free space method. The scattering parameter $\mathrm{S}_{21}$ was used to measure electromagnetic absorption. In a two-port system, $\mathrm{S}_{21}$ parameter determines the ratio of the output power-wave to the input power-wave and is calculated in $\mathrm{dB}$ as follows:

$$
S_{21}(d B)=10 \log \frac{P_{2}}{P_{1}}(d B)
$$

A Rohde \& Schwarz FSH6 model spectrum analyzer was used in the study. Generator output on the spectrum analyzer was used as a source. The electromagnetic wave was sent with the antenna connected to the generator output and the electromagnetic wave reaching through the second antenna placed opposite was detected. Data were observed and recorded via a laptop connected to the spectrum analyzer. Lead material was used to avoid reflections that may occur in the anechoic chamber used in this study.

The inner boundary of the far-field region of an antenna is defined by the following equation [30]:

$$
R>\frac{2 D^{2}}{\lambda}
$$

where $\mathrm{R}$ is the distance, $\mathrm{D}$ is the antenna dimension and $\lambda$ is the wavelength. Also, geometric condition $(\mathrm{R} \gg \mathrm{D})$ and optical condition $(\mathrm{R} \gg \lambda)$ must be satisfied to be in the far-field region. The longest length of the microstrip Log-Periodic Dipole Array (LPDA) is $0.19 \mathrm{~m}$. In this antenna size, the far-field boundary should be around $0.75 \mathrm{~m}$ considering the far-field boundary conditions. The LPDA antenna designed as a receiver and transmitter is shown in Figure 5.

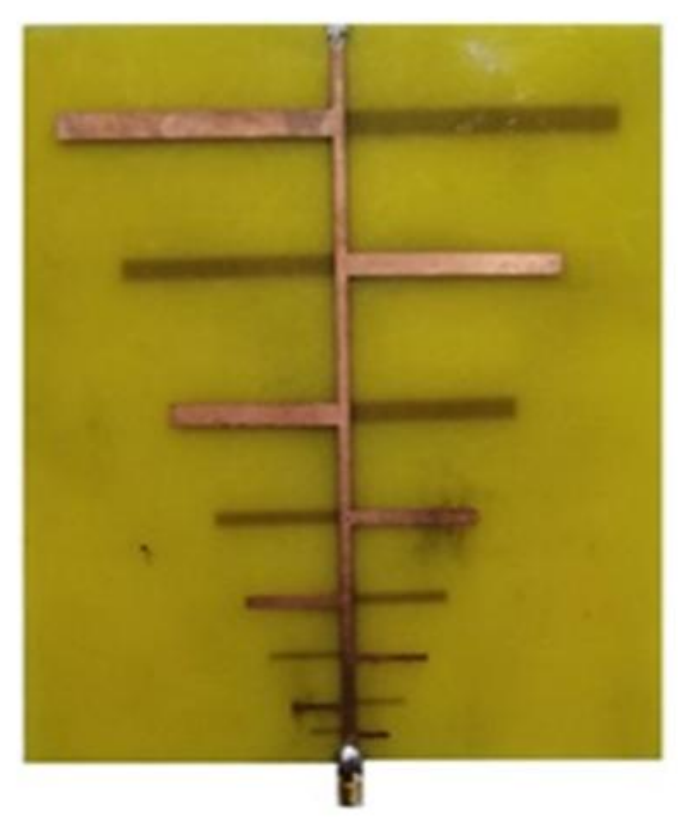

Figure 5. Fabricated microstrip LPDA antenna. 
In the measurement technique that we apply in the study, the absorption effectiveness of the manufactured material, i.e. the sum of reflection, absorption, and repeated reflection losses in the sample will be found. The experimental setup is shown in Figure 6. The outer wall of the anechoic chamber is covered with a 2 mm thick aluminum plate. The walls, ceiling, and floor inside the chamber were lined with the pyramidal foam absorbers which are the most used material in anechoic chambers for coping with the reflections generated by the electromagnetic signals inside the experimental setup. In the middle of the anechoic chamber, between the antennas as a direction, an interface is formed from an aluminum plate and the middle is left empty so that the sample material can be placed. With the help of the assembly apparatus created on the middle surface, the sample material can be fixed here and measurement can be made.

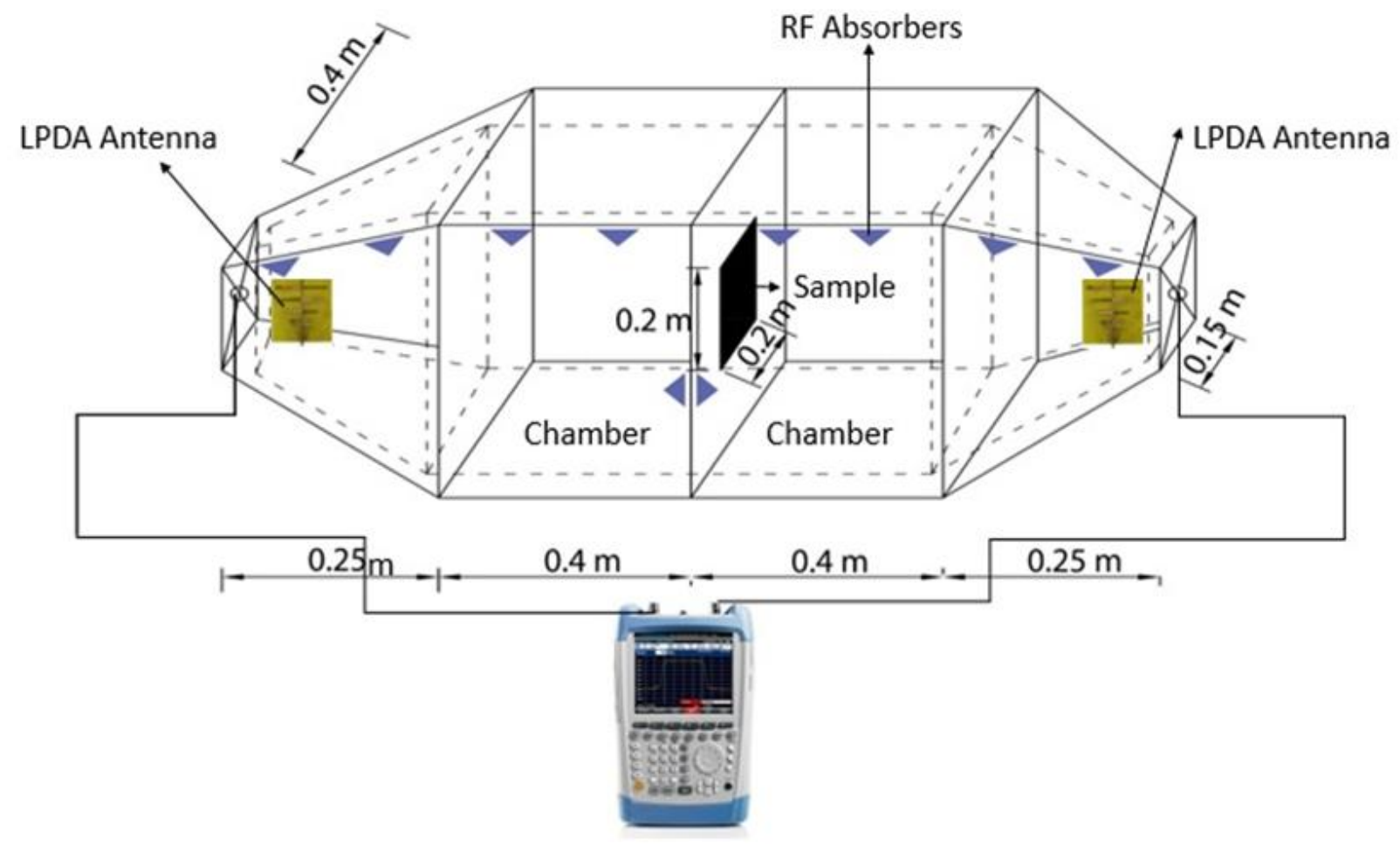

Figure 6. Experimental setup.

Two different calibrations are mentioned in the study. The first of these is the calibration of the device. The spectrum analyzer was calibrated before the measurements. The spectrum analyzer is switched to calibration mode and according to the message on the screen the line was first terminated open, then terminated with the load. The device has processed these measurements and completed its calibration in a way that eliminates the effect of transmission lines and antennas. This process was repeated in the range of 750 $1500 \mathrm{MHz}$ and in the range of $1500-3000 \mathrm{MHz}$ to ensure reliable measurement results. The second calibration is the differential process that reveals the effect of the material on the empty environment (with no material in between). After the device was calibrated, measurements were taken with no material in between, and these measurements were taken as reference. The measurements were repeated by placing the absorption materials produced in between. Absorption effectiveness was demonstrated by taking the difference between the first recorded reference measurement and the measurement made by placing the material in between. Due to the differential process, possible measurement errors were minimized. 


\section{Results and discussion}

The electromagnetic absorption effectiveness of the samples was measured in the frequency range of $750 \mathrm{MHz}$ - $3000 \mathrm{MHz}$. The limit for the absorption effectiveness was taken as 10dB, which is accepted in the literature. In order to evaluate the absorption effectiveness more precisely, the graphics were divided into two parts, the first group is in the frequency range of $750 \mathrm{MHz}-1500 \mathrm{MHz}$, the second group is in the frequency range of 1500MHz-3000 MHz.

The absorption effectiveness values of the composite boards with office paper as a reinforcement element and with boric acid added by weight of $0 \%, 5 \%, 10 \%, 20 \%$, and $30 \%$ are shown in Figure 7 . While a significant difference was observed in the frequency range of $750-1500 \mathrm{MHz}$ according to the contribution rate, no significant effect of the contribution was observed in the frequency range of 1500-3000 MHz. A different absorption effect was found from other additive ratios at about $2800 \mathrm{MHz}$. It was determined that the boric acid-added office paper board had a significant absorption in different frequency regions between 1500-3000 MHz. The absorption effectiveness was recorded close to $30 \mathrm{~dB}$ at two different frequencies.
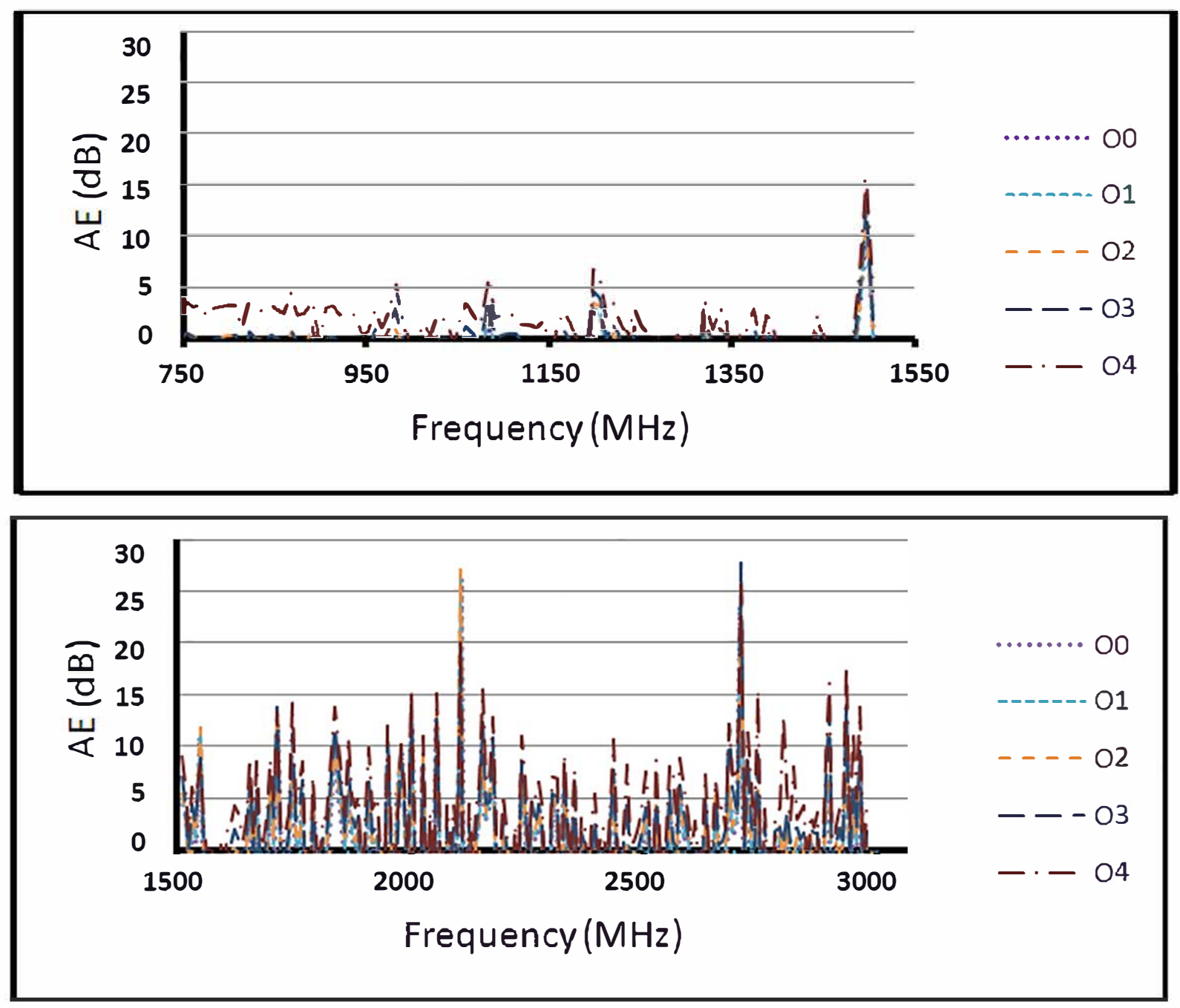

Figure 7. Change in the absorption effectiveness of boric acid-added office paper composite board. 
The absorption effectiveness values of the composite boards with newsprint as a reinforcement element and with boric acid added by weight of $0 \%, 5 \%, 10 \%, 20 \%$, and $30 \%$ are shown in Figure 8 . In the $20 \%$ boric acid added composite board consisting of newsprint, an average absorption of $20 \mathrm{~dB}$ was recorded at all frequencies in the range of 750-3000 MHz. The fact that this value was recorded less in boards with $30 \%$ boric acid can be explained as the resonance effect may have occurred. Around the frequency of $2100 \mathrm{MHz}$, an absorption of 40 $\mathrm{dB}$ in the board with $20 \%$ boric acid and $20 \mathrm{~dB}$ in the board with $30 \%$ boric acid was recorded. No significant differences in absorption were noted for boards with $5 \%$ and $10 \%$ additions.
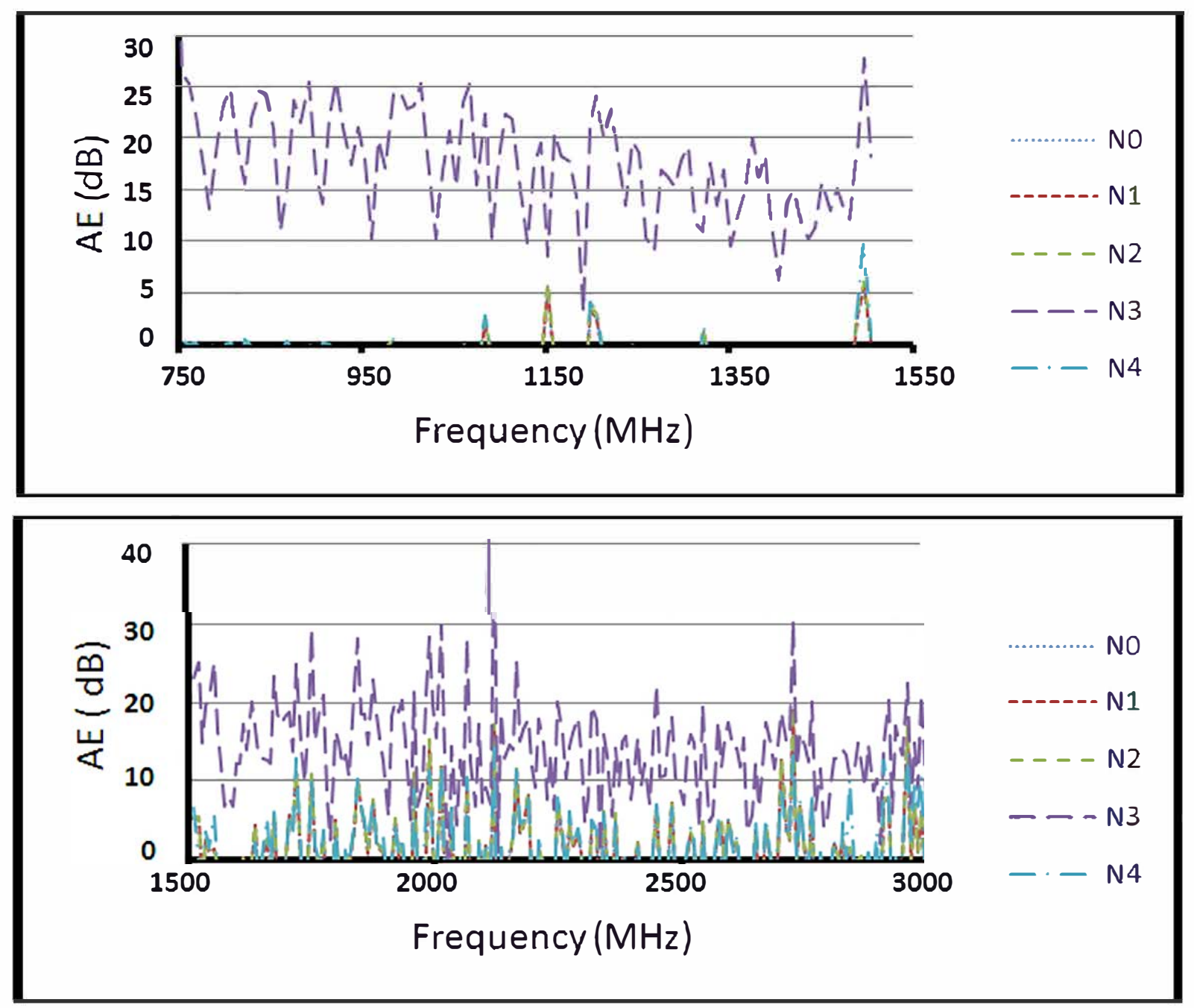

Figure 8. Change in the absorption effectiveness of boric acid-added newsprint composite board.

The absorption effectiveness values of the composite boards with cardboard paper as a reinforcement element and with boric acid added by weight of $0 \%, 5 \%, 10 \%, 20 \%$, and $30 \%$ are shown in Figure 9 . No significant effect of the contribution was observed in the frequency range of $750-1500 \mathrm{MHz}$ and $1500-3000 \mathrm{MHz}$ according to the rate of contribution. An absorption effect of $15 \mathrm{~dB}$ was found around the frequency of 1500 $\mathrm{MHz}$. A different absorption effect was found from other additive ratios at about $2900 \mathrm{MHz}$. An absorption effect of $30 \mathrm{~dB}$ in the board with $20 \%$ and $30 \%$ boric acid additions was recorded. 

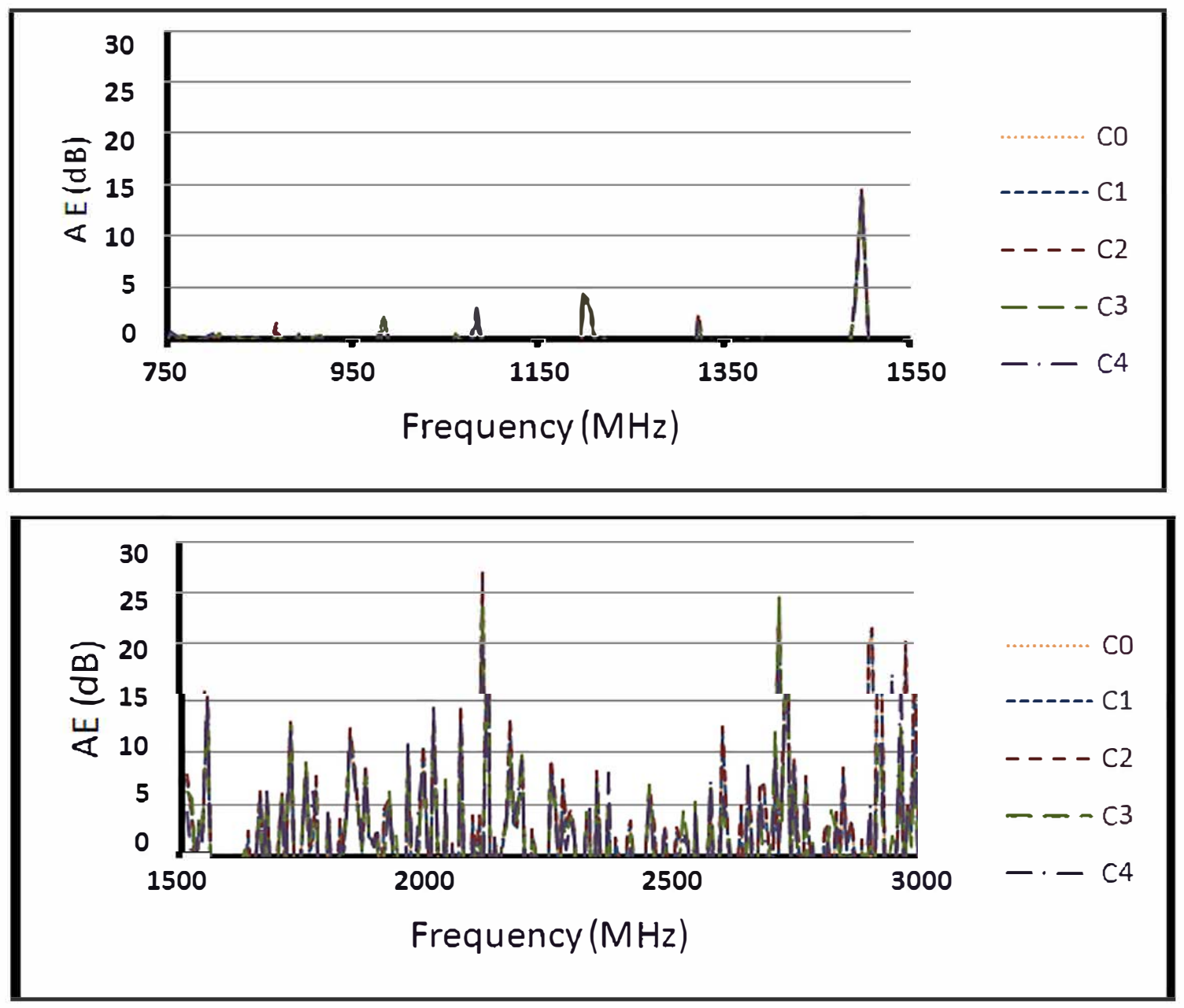

Figure 9. Change in the absorption effectiveness of boric acid-added cardboard paper composite board.

The comparison of the absorption effectiveness results of office paper, newsprint, and cardboard paper composite boards to which boric acid was added is given in Figure 10. The aim of the measurements made by keeping the contribution rate of each board constant is to determine the significant effects of the wastepaper difference in terms of absorption. When the measurements made were evaluated, although the change in the type of wastepaper did not show a significant difference in terms of absorption effectiveness in general, an effect that would contribute positively to absorption in the frequency range of 750-3000 MHz was noted only in newsprint.

By keeping the matrix material constant, different mineral substances are added and the absorption effectiveness of mineral substances is presented in Figure 11. Office paper was used as a reinforcement element and boards were manufactured by forming a film layer by coating mineral materials on the surface. In the aluminum added board, absorption effectiveness of $25 \mathrm{~dB}$ at $1200 \mathrm{MHz}$, around $30 \mathrm{~dB}$ at $1320 \mathrm{MHz}$ and about $40 \mathrm{~dB}$ at $1500 \mathrm{MHz}$ and $1800 \mathrm{MHz}$ was recorded. In the copper added board, absorption effectiveness of $30 \mathrm{~dB}$ in the frequency range of $1150 \mathrm{MHz}-1250 \mathrm{MHz}$ and $1300 \mathrm{MHz}-1350 \mathrm{MHz}$, at $1800 \mathrm{MHz}, 2300 \mathrm{MHz}$ and 2800 $\mathrm{MHz}$ was determined. The absorption effectiveness of boric acid added board was recorded $20 \mathrm{~dB}$ at $1500 \mathrm{MHz}$ and $30 \mathrm{~dB}$ at $2800 \mathrm{MHz}$. 

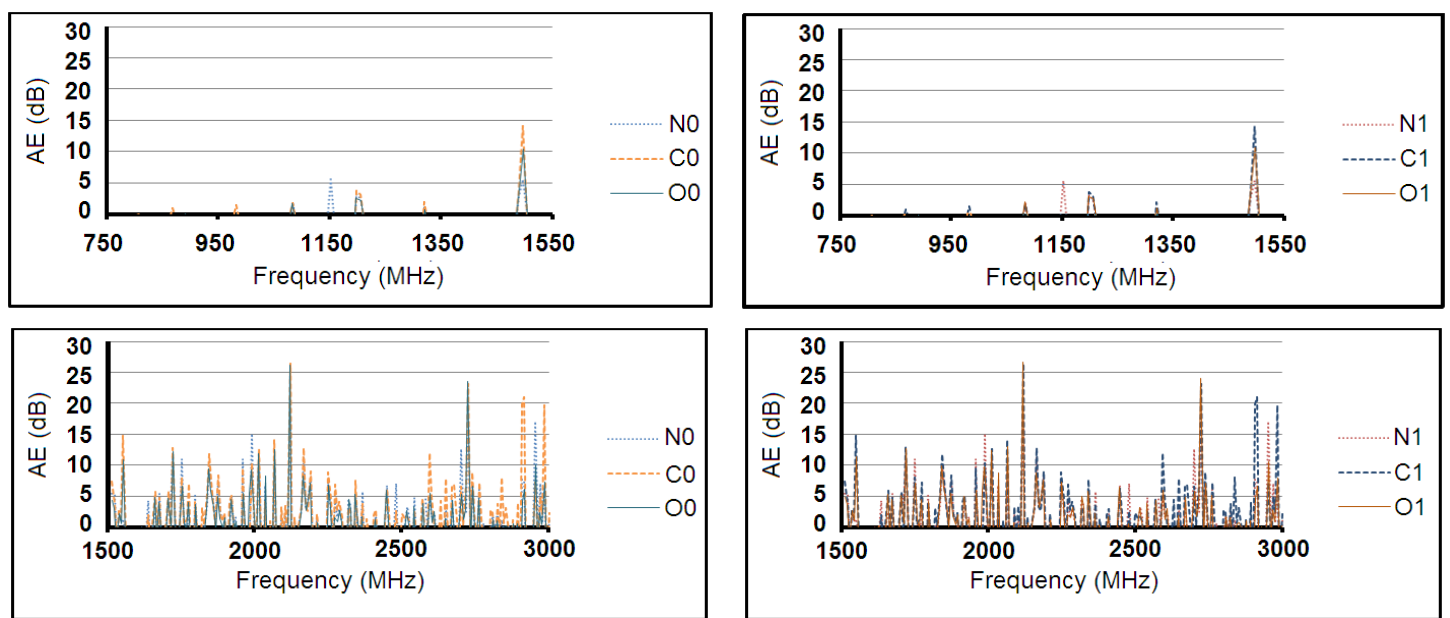

a
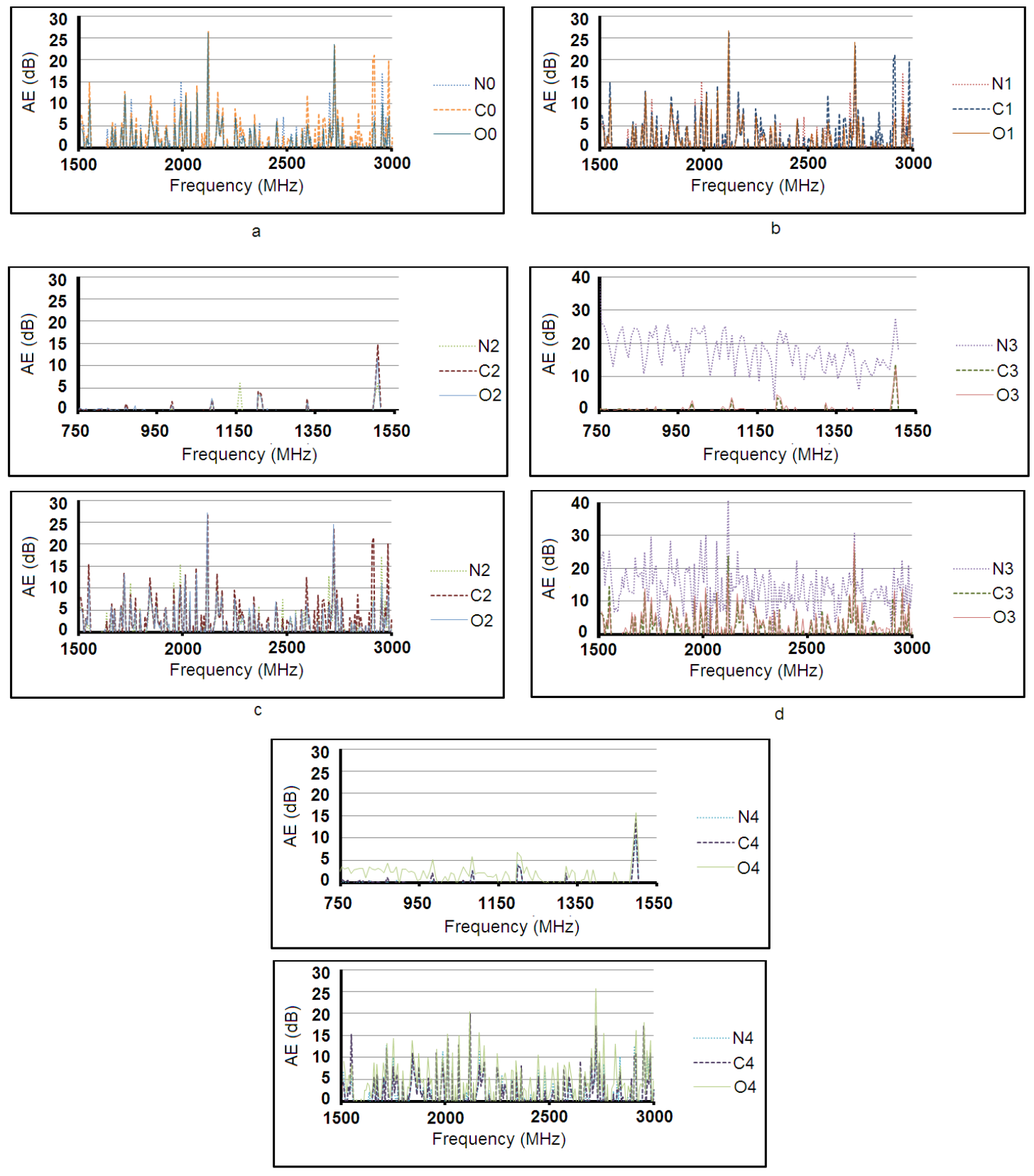

e

Figure 10. Change in the absorption effectiveness (a) $0 \%$ boric acid (b) $5 \%$ boric acid (c) $10 \%$ boric acid (d) $20 \%$ boric acid (e) $30 \%$ boric acid. 

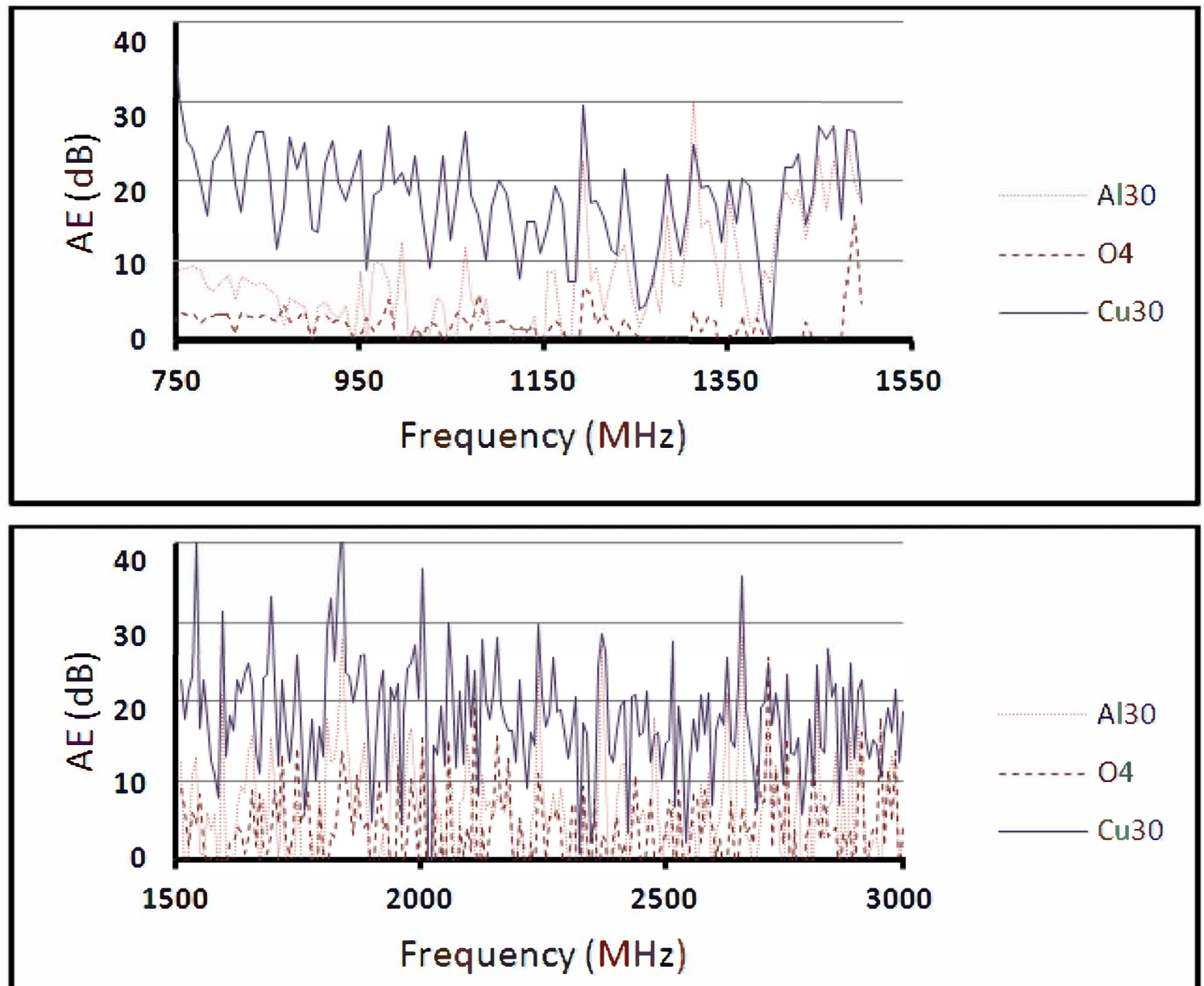

Figure 11. Change in the absorption effectiveness of $30 \%$ aluminum, copper and boric acid-added office paper composite board.

According to the measurement results of the manufactured samples, the appropriate technologies using the frequency bands between $750 \mathrm{MHz}$ and $3000 \mathrm{MHz}$ for each material are given in Table 6 .

\section{Conclusion}

In this paper, it was aimed to develop a new and environmentally friendly material within the framework of taking measures to minimize the unwanted effects of electromagnetic waves. As a result of the findings obtained in the study, the purpose of the measurements made by keeping the contribution rate of each board constant was to determine the significant effects of the difference in wastepaper in terms of absorption. In Table 6 , it can be found which type of boric acid-added composite board could be used as a potential electromagnetic absorption material for technologies using the frequency bands between $750 \mathrm{MHz}$ and $3000 \mathrm{MHz}$. Table 6 emphasizes the importance of our study.

When the measurements made were evaluated, although the change of wastepaper type did not show a significant difference in terms of absorption efficiency, an effect that would contribute positively to absorption in the frequency range of $750-3000 \mathrm{MHz}$ was recorded only in newsprint. The carbon content of the ink in 
KAYA et al./Turk J Elec Eng \& Comp Sci

Table 6. Potential application for boric acid-added composite boards

\begin{tabular}{|c|c|c|c|c|c|c|c|c|c|c|c|c|c|c|c|c|}
\hline \multicolumn{17}{|c|}{ Samples } \\
\hline $\begin{array}{l}\text { Technologies } \\
\text { (Band) }\end{array}$ & $\begin{array}{l}\text { Frequency } \\
(\mathrm{MHz})\end{array}$ & No & $\mathrm{C} 0$ & $\mathrm{O} 0$ & N1 & $\mathrm{C} 1$ & $\mathrm{O} 1$ & N2 & $\mathrm{C} 2$ & $\mathrm{O} 2$ & N3 & C3 & O3 & N4 & $\mathrm{C} 4$ & $\mathrm{O} 4$ \\
\hline $\begin{array}{l}\text { Digital Dividend } \\
(\mathrm{EU})(20)\end{array}$ & 800 & & & & & & & & & & $\sqrt{ }$ & & & & & \\
\hline $\begin{array}{l}\text { Extended GSM } \\
(8)\end{array}$ & 900 & & & & & & & & & & $\sqrt{ }$ & & & & & \\
\hline $\begin{array}{l}\text { L-Band } \\
(32,45,50,51)\end{array}$ & 1500 & & $\sqrt{ }$ & $\sqrt{ }$ & & $\sqrt{ }$ & $\sqrt{ }$ & & $\sqrt{ }$ & $\sqrt{ }$ & $\sqrt{ }$ & $\sqrt{ }$ & $\sqrt{ }$ & $\sqrt{ }$ & $\sqrt{ }$ & $\sqrt{ }$ \\
\hline $\begin{array}{l}\text { AWS-1 } \\
\text { (4) }\end{array}$ & 1700 & $\sqrt{ }$ & $\sqrt{ }$ & $\sqrt{ }$ & $\sqrt{ }$ & $\sqrt{ }$ & & & $\sqrt{ }$ & $\sqrt{ }$ & $\sqrt{ }$ & $\sqrt{ }$ & $\sqrt{ }$ & & & $\sqrt{ }$ \\
\hline $\begin{array}{l}\text { PCS } \\
(2)\end{array}$ & 1900 & & & & & & & & & & $\sqrt{ }$ & & & & & \\
\hline $\begin{array}{l}\text { IMT } \\
(34)\end{array}$ & 2000 & $\sqrt{ }$ & & & $\sqrt{ }$ & & & $\sqrt{ }$ & & & $\sqrt{ }$ & $\sqrt{ }$ & $\sqrt{ }$ & $\sqrt{ }$ & $\sqrt{ }$ & \\
\hline $\begin{array}{l}\text { IMT } \\
(1)\end{array}$ & 2100 & & $\sqrt{ }$ & $\sqrt{ }$ & & $\sqrt{ }$ & $\sqrt{ }$ & & $\sqrt{ }$ & $\sqrt{ }$ & $\sqrt{ }$ & & & & $\sqrt{ }$ & $\sqrt{ }$ \\
\hline $\begin{array}{l}\text { S-Band } \\
(40)\end{array}$ & 2300 & & & & & & & & & & $\sqrt{ }$ & & & & & \\
\hline $\begin{array}{l}\text { S-Band } \\
(53)\end{array}$ & 2500 & & & & & & & & & & $\sqrt{ }$ & & & & & \\
\hline $\begin{array}{l}\text { IMT-E } \\
(7,38,69)\end{array}$ & 2600 & & $\sqrt{ }$ & & & $\sqrt{ }$ & & & $\sqrt{ }$ & & $\sqrt{ }$ & & & & & \\
\hline
\end{tabular}

newsprint increased the conductivity of the material. The addition of boric acid at the appropriate rate created the marginal effect and maximum absorption was observed in the N3 sample.

Boric acid absorbed the expected values in certain frequency ranges. Apart from the use of boric acid as a powder, it has been determined that applying it as a layer on the surface is also effective in absorption. The application of the additive in the form of a film layer on the surface gave more successful results in terms of absorption effectiveness than the application in powder form.

\section{Acknowledgment}

This work was supported by project number 1180760 through the Scientific and Technological Research Council of Turkey (TÜBİTAK).

\section{References}

[1] Adam AA, Gülez K, Köroğlu S. Stray magnetic field distributed around a PMSM. Turkish Journal of Electrical Engineering \& Computer Sciences 2011; 19 (1): 119-131. doi:10.3906/elk-1003-404

[2] Tomovski B,Gräbner F, Hungsberg A, Kallmeyer C, Linsel M. Effects of electromagnetic field over a human body, SAR simulation with and without nanotextile in the frequency range 0. 9-1.8 GHz. Journal of Electrical Engineering 2011; 62 (6):349-354. doi:10.2478/v10187-011-0055-6 
KAYA et al./Turk J Elec Eng \& Comp Sci

[3] Kivrak EG, Yurt KK, Kaplan AA, Alkan I, Altun G. Effects of electromagnetic fields exposure on the antioxidant defense system. Journal of Microscopy and Ultrastructure 2017; 5 (4): 167-176. doi:10.1016/j.jmau.2017.07.003

[4] Başyiğit İB, Genç A, Helhel S. Effect of orientation of RF sources maintained within the enclosures on electrical shielding effectiveness performance. Turkish Journal of Electrical Engineering \& Computer Sciences $2019 ; 27$ (4): 3088-3097. doi:10.3906/elk-1902-68

[5] Von Klemperer CJ, Maharaj D. Composite electromagnetic interference shielding materials for aerospace applications. Composite Structures 2009; 91 (4): 467-472. doi:10.1016/j.compstruct.2009.04.013

[6] Cakir M, Kockal NU, Ozen S, Kocakusak A, Helhel S. Investigation of electromagnetic shielding and absorbing capabilities of cementitious composites with waste metallic chips. Journal of Microwave Power and Electromagnetic Energy 2017; 51: 31-42. doi:10.1080/08327823.2017.1300118

[7] Araz İ. The measurement of shielding effectiveness for small-in-size ferrite-based flat materials. Turkish Journal of Electrical Engineering \& Computer Sciences 2018; 26: 2996-3006. doi:10.3906/elk-1803-162

[8] Kuruvilla J, Runcy W, Gejo G. Materials for Potential EMI Shielding Applications: Processing, Properties and Current Trends. Amsterdam: Elsevier, 2020.

[9] Cheng HC, Chen CR, Hsu SH, Cheng KB. Electromagnetic shielding effectiveness and conductivity of PTFE/Ag/MWCNT conductive fabrics using the screen printing method. Sustainability 2020; 12 (15): 1-11. doi:10.3390/su12155899

[10] Helhel S, Kocakusak A, Sunel M. Determining loss tangent values of dry granite for potential S-band applications. Microwave and Optical Technology Letters 2020; 62: 3476-3484. doi:10.1002/mop.32494

[11] Agarwal BD, Broutman LJ, Chandrashekhara K. Analysis and Performance of Fiber Composites. Hoboken, NJ, USA: John Wiley \& Sons, 2018.

[12] Springer A, Rose M, Ryu R. Eco blocks: Nontraditional use for mixed wastepaper. Journal of Environmental Engineering 1996; 122 (5): 437-444. doi:10.1061/(ASCE)0733-9372(1996)122:5(437)

[13] Davis G, Song J. Biodegradable packaging based on raw materials from crops and their impact on waste management. Industrial Crops and Products 2006; 23 (2): 147-161. doi:10.1016/j.indcrop.2005.05.004

[14] Fugetsu B, Sano E, Sunada M, Sambongi Y, Shibuya T et al. Electrical conductivity and electromagnetic interference shielding efficiency of carbon nanotube/cellulose composite paper. Carbon 2008; 46 (9): 1256-1258. doi:10.1016/j.carbon.2008.04.024

[15] Sangrutsamee V, Srichandr P, Poolthong N. Re-pulped waste paper-based composite building materials with low thermal conductivity. Journal of Asian Architecture and Building Engineering 2012; 11 (1): $147-151$. doi:10.3130/jaabe.11.147

[16] Ozdemir F, Kargi A. Electromagnetic waves and human health. In: Zhurbenko V (editor). Electromagnetic Waves. IntechOpen, 2011, pp. 473-492.

[17] Güler S, Yenikaya S. Analysis of shielding effectiveness by optimizing aperture dimensions of a rectangular enclosure with genetic algorithm. Turkish Journal of Electrical Engineering \& Computer Sciences 2021; 29 (2): $1015-1028$. doi:10.3906/elk-2005-113

[18] Naito K, Mizumoto T, Takahashi M, Kunieda S. Anechoic chamber having multi-layer electromagnetic wave absorbers of sintered ferrite and ferrite composite membrane. In: IEEE Symposium on Electromagnetic Compatibility; Chicago, IL, USA; 1994. pp. 402-407.

[19] Jiaoyan S, Jing Z, Yimin L, Bo L, Xiaopeng, Z. High-performance dendritic metamaterial absorber for broadband and near-meter wave radar. Applied Physics A 2019; 125: 1-11. doi:10.1007/s00339-019-2604-y

[20] Håkanssona E, Amietb A, Nahavandic S, Kaynak A. Electromagnetic interference shielding and radiation absorption in thin polypyrrole films. European Polymer Journal 2007; 43 (1): 205-213. doi:10.1016/j.eurpolymj.2006.10.001 
KAYA et al./Turk J Elec Eng \& Comp Sci

[21] Raju VSR. Synthesis of non-stoichiometric zinc ferrite for electromagnetic wave absorber applications. Materials Science and Engineering 2017; 224: 88-92. doi:10.1016/j.mseb.2017.07.012

[22] Kaya Aİ, Çifci A, Gözel MA, Kahriman M. Electromagnetic absorption efficiency of aluminum doped composite materials recycled from waste Tetra Pak packages in the frequency range $1.8 \mathrm{GHz}$ to $5 \mathrm{GHz}$. Materials Research Express 2020; 7: 1-11. doi:10.1088/2053-1591/abd0d5

[23] Wang Z, Fu X, Zhang Z, Jiang Y, Waqar M et al. Based metasurface: Turning waste-paper into a solution for electromagnetic pollution. Journal of Cleaner Production 2019, 234: 588-596. doi:10.1016/j.jclepro.2019.06.239

[24] Çifci A, Kaya Aİ. Electromagnetic shielding effectiveness of mineral doped waste paper fiber. Acta Physica Polonica A 2018; 134 (1): 265-267. doi:10.12693/APhysPolA.134.265

[25] Eti Mine. Boric Acid, Product Technical Data Sheet, Ankara, 2019.

[26] TAPPI T 205 sp-02. Handsheets for Physical Tests of Pulp. TAPPI Press, Atlanta, GA, 2002.

[27] Kocakusak A, Colak B, Helhel S. Frequency dependent complex dielectric permittivity of rubber and magnolia leaves and leaf water content relation. Journal of Microwave Power and Electromagnetic Energy 2016; 50: 294-307. doi:10.1080/08327823.2016.1254135

[28] IEEE Std 299-2006. IEEE Standard Method for Measuring the Effectiveness of Electromagnetic Shielding Enclosures, (Revision of IEEE Std 299-1997), 2007.

[29] Geetha S, Kumar KKS, Rao CRK, Vijayan M, Trivedi DC. EMI shielding: Methods and materials-A review. Journal of Applied Polymer Science 2009; 112 (4): 2073-2086. doi:10.1002/app.29812

[30] Balanis CA. Antenna Theory: Analysis and Design. Hoboken, NJ, USA: John Wiley \& Sons, 2016. 